\title{
Peertechz
}

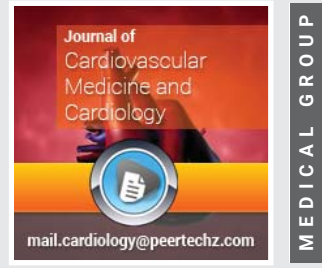

Research Article

\section{The effect of the}

\section{sociodemographic determinants of self-monitoring of blood}

\section{pressure}

\section{Addisu Dabi Wake ${ }^{1 *}$, Daniel Mengistu Bekele², Yohannes Ayalew Bekele ${ }^{2}$, Techane Sisay Tuji ${ }^{1}$ and Desalegn Tariku Jaleta $^{3}$}

${ }^{1}$ Nursing Department, College of Health Sciences, Arsi University, Asella, Ethiopia

${ }^{2}$ School of Nursing and Midwifery, College of Health Sciences, Addis Ababa University, Addis Ababa, Ethiopia

${ }^{3}$ School of Nursing, Department of Surgical, College of Medicine and Health Sciences, University of Gondar, Gondar, Ethiopia
Received: 19 March, 2021

Accepted: 31 March, 2021

Published: 01 April, 2021

*Corresponding author: Addisu Dabi Wake, Nursing Department, College of Health Sciences, Arsi University, 393/04, Asella, Ethiopia, Tel: +251 9102867 66; Email: addansa12@gmail.com

\section{ORCID: https://orcid.org/0000-0003-1219-0836}

Keywords: Sociodemographic; Blood pressure; Determinants; Self-monitoring of blood pressure; Hypertension

https://www.peertechz.com

\section{Check for updates}

\section{Abstract}

Introduction: Self-monitoring of Blood Pressure (BP) among hypertensive patients is a significant for the management and prevention of hypertension related complications such as atherosclerosis, Heart Failure (HF), Coronary Artery Disease (CAD), stroke, kidney disease, and peripheral arterial disease.

Objective: The aim of the present study was to determine the effect of the sociodemographic determinants of Self-monitoring of BP in hypertensive subjects.

Methods: A cross-sectional survey was done on four hundred hypertensive individuals on follow-up at selected hospitals in Arsi Zone, Ethiopia. The data collection period was from March ten to April eight, 2019.

Result: In the present study, four hundred participants were included into the study. Age $\geq 60$ years $[\mathrm{AOR}=2.01,95 \% \mathrm{Cl}(1.82,10.05), \mathrm{p}=0.012]$, higher education [AOR=2.97, 95\% Cl $(1.85,14.33), p=0.002]$, governmental employed [AOR=1.56, 95\% Cl $(1.08,7.48), p=0.023]$, urban residents [AOR=1.61, 95\% Cl $(1.17,6.67), p=0.007]$, having a monthly income of $>3500$ Ethiopian birr $[\mathrm{AOR}=2.46,95 \% \mathrm{Cl}(1.87,9.32), \mathrm{p}=0.006$ ] were factors significantly associated with self-monitoring of $\mathrm{BP}$ in the multivariable logistic regression analysis.

Conclusion: In the present study; young adults, attended lower education, unemployed, rural residents, low monthly income patients were found to have poor selfmonitoring of BP practice. Since, these patients are affected in particular, all the concerned bodies should actively participate to prevent or minimize this critical problem. During this, health education and training, on self-monitoring of BP may be required to take place.

\section{Introduction}

Hypertension is defined as a situation of a higher systemic BP that causes a considerable escalation of cardiovascular risk [1]. It is a systolic $\mathrm{BP}$ of $\geq 140 \mathrm{~mm} \mathrm{Hg}$ and a diastolic $\mathrm{BP}$ of $\geq 90 \mathrm{~mm} \mathrm{Hg}$ [2]. When $\mathrm{BP}$ is elevated, it will lead to complications such as; $\mathrm{HF}, \mathrm{CAD}$, ischemic and hemorrhagic stroke, renal impairment, peripheral vascular disease, and retinal hemorrhage [3]. Hypertension is the major risk factors for most of various Cardiovascular Disease (CVD) occurred thru lifespan [4]. If it is not controlled, it will elevate risk of incidence of $\mathrm{HF}$ and other adversative cardiovascular consequences [5].

Hypertension is among the main and preventable risk factors of hemorrhagic and ischemic stroke, $\mathrm{HF}, \mathrm{CAD}$, and chronic kidney disease [6]. Since hypertension is a silent killer 
[7] and also the majority of the individuals do not show any symptoms completely [8,9], It is significant to take the benefit of the premature warning signal through measuring our BP regularly [7]. So that, the warning signal of hypertension can only be noticed through this approache [9].

Self-monitoring of BP is a constant measurement of BP by a subject at home or anywhere else outdoor the clinic setting using a personal $\mathrm{BP}$ measuring device $[10,11]$. Concerning to the Self-monitoring of BP devices, its progress in the utilization and its availability has been realized due to the increasing issue of hypertension [12]. Self-monitoring of BP would get better access to services and worth of care for subjects with hypertension [10]. Further, it is a vital part of hypertension control. But, the absence in involvement of their doctors created misinterpretation and prohibited the real merit of selfmonitoring of $\mathrm{BP}[13]$.

Hypertension leftovers an enormous community health and economic problem worldwide irrespective of current improvement in the trend of BP control. It is an autonomous predictor of CVD and completely causes mortality [14]. The raised $\mathrm{BP}$ increases the chance of getting kidney diseases, heart attack, HF, and stroke. There should be consideration to the increased SBP as a main risk factor for CVDs [2]. The CVD is a core cause of disability and premature death globally while the hypertension is one of the principal causes [1]. The impact of hypertension is extensive, the proportion and the health consequences of uncontrolled hypertension make it amongst the world's furthermost lethal disease [15]. The magnitude of hypertension was $40 \%$ and $46 \%$ worldwide and in African respectively [16] while $19.6 \%$ in Ethiopia [17].

Hypertension is the principal cause of CVD and early death globally. Owing to the extensive use of antihypertensive medications, worldwide mean BP has continued persistent [18]. In the past 25 years, the assessed related deaths of subjects with elevated SBP levels is augmented markedly globally [19]. It was also detected as risk factors for intrauterine growth restriction in pregnant women [20]. Between 1990 and 2015 years globally, the expected rate of elevated SBP and linked yearly deaths were augmented from 17,307 to 20,526 per 100 000 persons and 97.9 to 106.3 per 100000 persons between 1990 and 2015 years respectively [21]. Whereas, in Africa, around 130.2 million cases of hypertension were approximated in 2010 and a projected rise to 216.8 million cases by 2030 [22].

About 1.4 billion individuals found to have a hypertension in 2010 globally. This has contributed for 18 million cardiovascular deaths yearly [23]. The magnitude of hypertension has been elevated in the past 2 to 3 decades in Africa. In this region, hypertension associated complications mainly stroke and heart failure are rising more common [24]. Self-monitoring of BP can produce a small, however clinically considerable decline in BP [25]. Self-monitoring of BP is a complementary system since individuals are participated with their self-care when they are self-monitoring their BP [26]. So that, even pharmacists can offer to the individual's awareness of BP control through encouraging them to perform self-monitoring BP to the subjects [27].
As briefly explained above, the impact of hypertension is rising globally. However, there is a lack of the study that has addressed the effect of the sociodemographic determinants on Self-monitoring of BP in the study area. Therefore, the purpose of the present study was to determine the effect of the sociodemographic determinants on Self-monitoring of BP. The outcome of the present study would alert the hospitals, health professionals, government, stakeholders and the researchers who are willing to done the study on the effect of the sociodemographic determinants on Self-monitoring of $\mathrm{BP}$ to manage and control the critical impact of hypertension which is rising overwhelmingly across the worldwide.

\section{Objectives}

General objective: To determine the effect of the sociodemographic determinants on Self-monitoring of blood pressure on hypertensive subjects at selected public hospitals in Arsi Zone, southeast Ethiopia.

Specific objective: To identify the effect of the sociodemographic determinants on Self-monitoring of blood pressure on hypertensive subjects at selected public hospitals in Arsi Zone, southeast Ethiopia.

\section{Methods}

\section{Study area, period and study design}

A cross-sectional survey was used among hypertensive individuals who were on follow up clinic at selected hospitals of Arsi Zone, which is found in southeast of Ethiopia. The study period was from March ten to April eight, 2019.

\section{Source population and study population}

The source population of the present study were all adult hypertensive patients visiting hospitals of Arsi zone while study population were selected individuals. During this survey, all subjects aged $\geq 18$ years and on follow-up at least for 6 months and willing to participate were included. Whereas, the study subjects who were excluded during the data collection were, who were severely ill, who were not mentally and physically capable of being interviewed.

\section{Sample size determination, sampling technique and pro- cedures}

During this survey, simple random sampling technique was used to select the four hospitals from seven public hospitals in the zone. Since survey was undertaken, all individuals attending for follow-up at selected hospitals were comprised in the study. The final sample size was four hundred.

\section{Study variables}

Dependent variables: Self-monitoring blood pressure

Independent variables: Age, gender, religion, ethnicity, educational level, marital status, occupation, residency, monthly income were socio-demographic variables. 


\section{Operational definitions}

Self-monitoring of BP: Is a self-measurement of BP by subjects at home or elsewhere outside the clinic setting. Whereas, they use a personal self-monitoring device for this purpose $[10,11]$.

Self-monitoring of BP: In the present study it was assessed by 'do you currently self-monitor your BP using a selfmonitoring BP device at home?' [28-30].

\section{Data collection instrument, Data collection procedures and Data quality control}

Data were collected by using a semi-structured questionnaire which was prepared by English. It was prepared after reviewing various related literature [28-35]. It has two sections; the sociodemographic characteristics of the participants and Blood pressure self-monitoring practice section. The pretest was done on $5 \%$ of the sample size. Training was given for data collectors and supervisors for 2 days. A total of $4 \mathrm{BSc}$ nurses' data collectors and 2 MSc nurses' supervisors were employed for this survey. The reliability analysis was done and a Cronbach's alpha value was 0.85 .

\section{Data processing and analysis}

Epi-Data version 4.2.0.0 was used for data entering and it was exported to SPSS version 21.0. Tables, figures and texts were used to summarize descriptive statistics. Bivariable and multivariable logistic regression analysis were used to identify independent variables associated with the dependent variables. Hosmer-Lemeshow's goodness-of-fit test for the dependent variable and the result was $\mathrm{p}$-value $=0.253$. Finally, p-values $<0.05$ was considered as statistically significant in the multivariable logistic regression.

\section{Results}

\section{Socio-demographic features of the study subjects}

A total of 400 hypertensive participants were included into the study giving the response rate of $97.6 \% .142(35.5 \%)$ of subjects were aged between 20-39 years, 150 (37.5\%) of them were aged between 40-59 years, and $108(27.0 \%)$ of them were aged $\geq 60$ years. $225(56.3 \%)$ of them were males and the rest of them were females. 282 (70.5\%) were Oromo and $118(29.5 \%)$ of them were non-Oromo ethnicity. Regarding to the religion, 187 (46.7\%) were orthodox, 159 (39.8\%) were Muslim, and $54(13.5 \%)$ were Protestant followers. 206 (51.5\%) of them had a primary education, $100(25.5 \%)$ of them had attended a secondary education, and $94(23.5 \%)$ of them had attended a higher education. 95 (23.8\%) of them were single, $160(40.0 \%)$ of them were married, $72(18.0 \%)$ of them divorced, $73(18.2 \%)$ of them widowed.

Concerning to the occupation, $96(24.0 \%)$ of them were governmental employed, and $304(76.0 \%)$ of them were unemployed. $242(60.5 \%)$ of them were urban residents while the rest of them were rural residents. Finally, 195 (48.8\%) of them had $<2500$ Ethiopian birr average monthly income, 99
(24.7\%) of them were had 2500-3500 Ethiopian birr average monthly income, and 106 (26.5\%) of them had >3500 Ethiopian birr average monthly income.

\section{Proportion of self-monitoring of BP across different so- ciodemographic variables}

From the participants who were aged $\geq 60$ years, the majority $14(13.0 \%)$ of them used self-monitoring of BP. From the patients' who were males, the majority 21 (9.3\%) of them used self-monitoring of BP. From the patients' who had higher education, the majority $14(14.9 \%)$ of them had used selfmonitoring of BP (Table 1).

\section{Sociodemographic factors affecting the use of self-mo- nitoring of BP}

Gender, age, ethnicity, religion, educational level, marital status, residency, monthly income, and occupation entered into bi-variable logistic regression analysis model were also moved into the multivariable analysis model. However, age, educational level, occupation, residency, and monthly income were factors significantly associated with self-monitoring of $\mathrm{BP}$ in the multivariable logistic regression analysis.

The odds of self-monitoring of BP in patients who were aged $\geq 60$ years were 2.01 times [AOR $=2.01,95 \%$ CI $(1.82$, 10.05), $\mathrm{p}=0.012$ ] higher than participants who were aged 20-39 years. The odds of self-monitoring of $\mathrm{BP}$ in patients who have attended higher education were 2.97 times [AOR=2.97, 95\%CI $(1.85,14.33), p=0.002]$ higher than who had primary education. Besides, the likelihood of having self-monitoring of BP among patients who were governmental employed were 1.56 times [AOR=1.56, 95\%CI $(1.08,7.48), \mathrm{p}=0.023]$ more likely to have self-monitoring of $\mathrm{BP}$ when compared to their opposite.

The likelihood of having self-monitoring of BP in patients who were urban residents were 1.61 times $[\mathrm{AOR}=1.61,95 \% \mathrm{CI}$ $(1.17,6.67), p=0.007]$ more likely to have self-monitoring of $\mathrm{BP}$ when compared to their opposites. Further, the patients who got monthly income of $>3500$ ETB were 2.46 [AOR=2.46, 95\%CI (1.87, 9.32), $\mathrm{p}=0.006$ ] more likely to have self-monitoring of BP when compared to those who got $<2500$ ETB (Table 2).

\section{Discussion}

The present study was done to determine the effect of the sociodemographic determinants on Self-monitoring of BP on hypertensive subjects. This is because identifying the effect of the sociodemographic determinants on Self-monitoring of BP on hypertensive individuals is a foundation for hypertension management to manage and control the complications, morbidity and mortality related to hypertension.

The odds of self-monitoring of BP in individuals who were aged $\geq 60$ years were 2.01 times $[\mathrm{AOR}=2.01,95 \% \mathrm{CI}(1.82,10.05)$, $\mathrm{p}=0.012]$ higher than participants who were aged 20-39 years. This finding was inconsistent with the cross-sectional study done in Karachi, Pakistan which reported that participants who were between the age of 40 and 59 years had a higher chance of owning a sphygmomanometer and self-monitoring of BP [34] 
Table 1: The proportion of Self-monitoring of BP Across Different Sociodemographic Variables among hypertensive patients who were on follow up clinic at selected hospitals in Arsi Zone, southeast Ethiopia, 2019. [n=400].

\begin{tabular}{|c|c|c|c|c|}
\hline \multirow{2}{*}{ Sociodemographic Variables } & \multirow{2}{*}{ Category } & \multicolumn{2}{|c|}{ Self-monitoring of BP } & \multirow{2}{*}{ Total } \\
\hline & & Monitor N (\%) & Nonmonitor N (\%) & \\
\hline \multirow{3}{*}{ Age } & $20-39$ & $8(5.6 \%)$ & $134(94.4 \%)$ & 142 \\
\hline & $40-59$ & $9(6.0 \%)$ & $141(94.0 \%)$ & 150 \\
\hline & $\geq 60$ & $14(13.0 \%)$ & $94(87.0 \%)$ & 108 \\
\hline \multirow{2}{*}{ Gender } & Male & $21(9.3 \%)$ & $204(90.7 \%)$ & 225 \\
\hline & Female & $10(5.7 \%)$ & $165(94.3 \%)$ & 175 \\
\hline \multirow{2}{*}{ Ethnicity } & Oromo & $22(7.8 \%)$ & $260(92.2 \%)$ & 282 \\
\hline & Non-Oromo & $9(7.6 \%)$ & $109(92.4 \%)$ & 118 \\
\hline \multirow{3}{*}{ Religion } & Orthodox & $18(9.6 \%)$ & $169(90.4 \%)$ & 187 \\
\hline & Muslim & $8(5.0 \%)$ & $151(95.0 \%)$ & 159 \\
\hline & Protestant & $5(9.3 \%)$ & $49(90.7 \%)$ & 54 \\
\hline \multirow{3}{*}{ Educational level } & Primary education & $11(5.3 \%)$ & $195(94.7 \%)$ & 206 \\
\hline & Secondary education & $6(6.0 \%)$ & $94(94.0 \%)$ & 100 \\
\hline & Higher education & $14(14.9 \%)$ & $80(85.1 \%)$ & 94 \\
\hline \multirow{4}{*}{ Marital status } & Single & $5(5.3 \%)$ & $90(94.7 \%)$ & 95 \\
\hline & Married & $14(8.8 \%)$ & $146(91.3 \%)$ & 160 \\
\hline & Divorced & $6(8.3 \%)$ & $66(91.7 \%)$ & 72 \\
\hline & Widowed & $6(8.2 \%)$ & $67(91.8 \%)$ & 73 \\
\hline \multirow[t]{2}{*}{ Occupation } & Governmental Employed & $9(9.4 \%)$ & $87(90.6 \%)$ & 96 \\
\hline & Unemployed & $22(7.2 \%)$ & $282(92.8 \%)$ & 304 \\
\hline \multirow[t]{2}{*}{ Residency } & Urban & $21(8.7 \%)$ & $221(91.3 \%)$ & 242 \\
\hline & Rural & $10(6.3 \%)$ & $148(93.7 \%)$ & 158 \\
\hline \multirow{3}{*}{ Monthly income } & $<2500$ ETB & $11(5.6 \%)$ & $184(94.4 \%)$ & 195 \\
\hline & 2500-3500 ЕTB & $6(6.1 \%)$ & $93(93.9 \%)$ & 99 \\
\hline & $>3500$ ETB & $14(13.2 \%)$ & $92(86.8 \%)$ & 106 \\
\hline
\end{tabular}

Table 2: Bivariate and Multivariate logistic regression Analysis of Sociodemographic Factors Associated with Self-monitoring of BP in Hypertensive subjects at selected Hospitals in Arsi Zone, southeast Ethiopia, 2019. [n=400].

\begin{tabular}{|c|c|c|c|c|c|c|}
\hline \multirow{2}{*}{ Sociodemographic Variables } & \multirow{2}{*}{ Category } & \multicolumn{2}{|c|}{ Self-monitoring of BP } & \multirow{2}{*}{ COR $(95 \% \mathrm{Cl})$} & \multirow{2}{*}{ AOR $(95 \% \mathrm{Cl})$} & \multirow{2}{*}{ p-value } \\
\hline & & Monitor & Nonmonitor & & & \\
\hline \multirow{3}{*}{ Age } & $20-39$ & $8(5.6 \%)$ & $134(94.4 \%)$ & 1 (Ref.) & 1 (Ref.) & \\
\hline & $40-59$ & $9(6.0 \%)$ & $141(94.0 \%)$ & $1.07(0.40,2.85)$ & $1.04(0.59,5.05)$ & 0.325 \\
\hline & $\geq 60$ & $14(13.0 \%)$ & $94(87.0 \%)$ & $2.50(1.01,6.18)$ & $2.01(1.82,10.05)$ & 0.012 \\
\hline \multirow{2}{*}{ Gender } & Male & $21(9.3 \%)$ & $204(90.7 \%)$ & $1.70(0.78,3.71)$ & $1.21(0.51,2.87)$ & 0.660 \\
\hline & Female & $10(5.7 \%)$ & $165(94.3 \%)$ & 1 (Ref.) & 1 (Ref.) & \\
\hline \multirow[t]{2}{*}{ Ethnicity } & Oromo & $22(7.8 \%)$ & $260(92.2 \%)$ & $1.03(0.46,2.30)$ & $1.12(0.45,2.75)$ & 0.809 \\
\hline & Non-Oromo & $9(7.6 \%)$ & $109(92.4 \%)$ & 1 (Ref.) & 1 (Ref.) & \\
\hline \multirow{3}{*}{ Religion } & Orthodox & 18(9.6\%) & $169(90.4 \%)$ & $1.04(0.37,2.96)$ & $1.01(0.32,3.14)$ & 0.989 \\
\hline & Muslim & $8(5.0 \%)$ & $151(95.0 \%)$ & $0.52(0.16,1.66)$ & $0.646(0.18,2.32)$ & 0.503 \\
\hline & Protestant & $5(9.3 \%)$ & $49(90.7 \%)$ & 1 (Ref.) & 1 (Ref.) & \\
\hline \multirow{3}{*}{ Educational level } & Primary education & $11(5.3 \%)$ & 195(94.7\%) & 1 (Ref.) & 1 (Ref.) & \\
\hline & Secondary education & $6(6.0 \%)$ & $94(94.0 \%)$ & $1.13(0.41,3.15)$ & $1.07(0.54,5.73)$ & 0.349 \\
\hline & Higher education & $14(14.9 \%)$ & $80(85.1 \%)$ & $3.10(1.35,7.13)$ & $2.97(1.85,14.33)$ & 0.002 \\
\hline \multirow{4}{*}{ Marital status } & Single & $5(5.3 \%)$ & $90(94.7 \%)$ & 1 (Ref.) & 1 (Ref.) & \\
\hline & Married & $14(8.8 \%)$ & $146(91.3 \%)$ & $0.62(0.18,2.12)$ & $1.88(0.61,5.80)$ & 0.273 \\
\hline & Divorced & $6(8.3 \%)$ & $66(91.7 \%)$ & $1.07(0.39,2.91)$ & $2.10(0.55,8.10)$ & 0.278 \\
\hline & Widowed & $6(8.2 \%)$ & $67(91.8 \%)$ & $1.02(0.31,3.31)$ & $1.66(0.434,6.31)$ & 0.460 \\
\hline \multirow[t]{2}{*}{ Occupation } & Governmental Employed & $9(9.4 \%)$ & $87(90.6 \%)$ & $1.33(0.59,2.99)$ & $1.56(1.08,7.48)$ & 0.023 \\
\hline & Unemployed & $22(7.2 \%)$ & $282(92.8 \%)$ & 1 (Ref.) & 1 (Ref.) & \\
\hline \multirow[t]{2}{*}{ Residency } & Urban & $21(8.7 \%)$ & $221(91.3 \%)$ & $1.41(0.64,3.07)$ & $1.61(1.17,6.67)$ & 0.007 \\
\hline & Rural & $10(6.3 \%)$ & $148(93.7 \%)$ & 1 (Ref.) & 1 (Ref.) & \\
\hline \multirow{3}{*}{ Monthly income in ETB } & $<2500$ & $11(5.6 \%)$ & $184(94.4 \%)$ & 1 (Ref.) & 1 (Ref.) & \\
\hline & $2500-3500$ & $6(6.1 \%)$ & $93(93.9 \%)$ & $1.08(0.39,3.01)$ & $1.06(0.34,3.39)$ & 0.911 \\
\hline & $>3500$ & $14(13.2 \%)$ & $92(86.8 \%)$ & $2.55(1.11,5.83)$ & $2.46(1.87,9.32)$ & 0.006 \\
\hline
\end{tabular}

Note: Figure in bold shows a statistically significant $(p<0.05)$

Abbreviations: COR: Crude Odds Ratio; AOR: Adjusted Odds Ratio; Cl: Confidence Interval; ETB: Ethiopian birr

Citation: Wake AD, Bekele DM, Bekele YA, Tuji TS, Jaleta DT (2021) The effect of the sociodemographic determinants of self-monitoring of blood pressure. J Cardiovasc Med Cardiol 8(2): 032-037. DOI: https://dx.doi.org/10.17352/2455-2976.000166 
This finding was also inconsistent with a study done in west Midlands, UK which has been reported that participants aged between 18 to 60 years were 1.5 times more likely to measure their own BP than older people (over 60 years) [30]. The difference might be due that the variation in the population characteristics the study conducted on.

The odds of self-monitoring of BP among patients who had higher education were 2.97 times [AOR $=2.97,95 \%$ CI $(1.85,14.33), p=0.002]$ higher than who had primary education. This finding was supported by the study conducted in Ghana, Karachi, Pakistan and Lombardy, a northern Italian region $[34,36,37]$ respectively. The possible justification is that the higher education provides the update of knowledge regarding to the self-monitoring of BP and the morbidity and mortality associated with the hypertension. Furthermore, the education supports to the patients to be alert of their full health status. In fact, education is the power of change.

The likelihood of having self-monitoring of BP among patients who were governmental employed were 1.56 times [AOR=1.56, 95\% CI $(1.08,7.48), p=0.023]$ more likely to have self-monitoring of BP when compared to their opposites. This finding was consistent with a study done in west Midlands, UK and Ghana [30,37] respectively. This could be due to that since the participants were employed, they had a salary which helps them to afford the cost of the self-monitoring BP device. So that, they would monitor their BP because they own the devices needed to do so.

The likelihood of having self-monitoring of BP in patients who were urban residents were 1.61times [AOR $=1.61,95 \%$ CI $(1.17,6.67), p=0.007]$ more likely to have self-monitoring of BP when compared to their opposites. This might be due to that the participants living in the urban residents are highly accessible to health-related information than that of the rural resident participants. This is true that information had the power to change the awareness of the communities towards the certain diseases and this is why health education program is created most of the time to alert the community regarding certain public issues.

The patients who had a monthly income of $>3500$ ETB were 2.46 [AOR=2.46, 95\% CI $(1.87,9.32), p=0.006$ ] more likely to have self-monitoring of $\mathrm{BP}$ when compared to those who got $<2500$ ETB. This finding was supported by a research done in Singapore, Asia and Ghana [35,37] respectively. The possible justification could be due to that if the participants had no scarcity of money to buy the devices, it is true that they will buy and monitor their own BP considering the seriousness of the disease. In fact, lack of money could be the barriers for the utilization of self-monitoring BP which is now evidenced by the association of the participants' high monthly income and the use of self-monitoring BP.

\section{Limitation of the study}

Finally, the accomplishment of the present study was not without limitations. There is no study conducted that show the effect of the sociodemographic determinants of self-monitoring of BP in Ethiopia and also in different counties adequately and this made the comparison problematic. However, hopefully this study could minimize such problem being a baseline for other researchers who will be willing to undertake the same study.

\section{Conclusion}

In the present study; age, education level, occupation, residency, and monthly income were factors that an association with self-monitoring of BP. The present study offers a foundation to support health professions for the management of hypertension. This can help them by giving insight about the factors that to be considered while intervening these patients. Through this it provides a significant information for the help of the societies' health and to prevent this problem. Finally, we suggest the government, healthcare provider, stakeholders, non-governmental organizations, and any other concerned bodies should actively participate to prevent or minimize this critical problem. During, this health education and training on self-monitoring of BP may be required to take place.

\section{Ethics approval and consent to participate}

The ethical clearance was obtained from the institutional review board of Addis Ababa University. Then, official letter was sent to the selected hospitals and permission was received. All the study participants were informed about the objectives of the study. Furthermore, they were insured about the confidentiality issue. Finally, verbal consents were obtained from each of them.

\section{Author contributions}

Addisu Dabi Wake, Daniel Mengistu Bekele, Yohannes Ayalew Bekele, Techane Sisay Tuji, and Desalegn Tariku Jaleta had contributed to conception of the study, data analysis and manuscript writing. Finally, all authors provide the final approval of the version to be published.

\section{Funding statement}

The present study was funded by Addis Ababa University.

\section{References}

1. Guidelines on Clinical and Programmatic Management of Major Non Communicable Diseases (2016) FEDERAL DEMOCRATIC REPUBLIC OF ETHIOPIA MINISTRY OF HEALTH: Addis Ababa. Link: https://bit.ly/3weLatL

2. The Seventh Report of the Joint National Committee on Prevention, Detection, Evaluation, and Treatment of High Blood Pressure; National Heart, Lung and Blood Institute; National High Blood Pressure Education Program. 2004. Link: https://bit.ly/3fxDJZ0

3. National Strategic Action Plan (NSAP) For Prevention \& Control Of NonCommunicable Diseases in Ethiopia; Federal Democratic Republic of Ethiopia Ministry of Health; 2014-2016. Link: https://bit.ly/3dlb72o

4. Kjeldsen SE (2018) Hypertension and cardiovascular risk: General aspects Pharmacol Res 129: 95-99. Link: https://bit.ly/3sKagOY

5. Iyer AS, Ahmed MI, Filippatos GS, Ekundayo OJ, Aban IB, et al. (2010) Uncontrolled hypertension and increased risk for incident heart failure in older adults with hypertension: findings from a propensity-matched prospective population study. J Am Soc Hypertens 4: 22-31. Link: https://bit.ly/3m8bKQR 
6. Walelgne W, Yadeta D, Feleke Y, Kebede T (2016) Guidelines on Clinical and Programmatic Management of Major Non Communicable Diseases: Federal Democratic Republic of Ethiopia Ministry of Health, Addis Ababa. Link: https://bit.ly/3m7uv6X

7. Schlein L (2018) WHO Targets High Blood Pressure. VOA. Link: https://bit.ly/39yf2aL

8. World Health Day (2013) A global brief on Hypertension: Silent killer, global public health crisis. World Health Organization, 20 Avenue Appia, 1211 Geneva 27, Switzerland. Link: https://bit.ly/3ucCjah

9. The Sixth Session of the African Union Conference of Ministers of Health. Status Report on Hypertension in Africa. Addis Ababa Ethiopia.

10. Centers for Disease Control and Prevention (2014) Self-Measured Blood Pressure Monitoring: Actions Steps for Clinicians. Atlanta, GA: Centers for Disease Control and Prevention. US Dept of Health and Human Services. Link: https://bit.ly/3rD1vF7

11. Goldstein A (2013) Self-Measured Blood Pressure Monitoring: Action Steps for Public Health Practitioners. Atlanta, GA: Centers for Disease Control and Prevention, US Dept of Health and Human Services. Link: https://bit.ly/3wjWVPy

12. George J, MacDonald T (2015) Home Blood Pressure Monitoring. Eur Cardiol 10: 95-101. Link: https://bit.ly/3wayUui

13. Abdullah A, Sajaratulnisah O (2011) The influence of self-owned home blood pressure monitoring (HBPM) on primary care patients with hypertension: A qualitative study. BMC Fam Pract 12: 143. Link: https://bit.ly/3me0MZV

14. Akinseye OA, Akinseye LI (2015) Home Blood Pressure Monitoring and Hypertension Control: Primary Health Care. 5: 182.

15. Bromfield S, Muntner P (2013) High blood pressure: the leading global burden of disease risk factor and the need for worldwide prevention programs. Curr Hypertens Rep 15: 134-136. Link: https://bit.ly/2PhosRm

16. Dzudie A, Kingue S, Dzudie A, Sliwa K, Mayosi B, et al. (2017) Roadmap to achieve $25 \%$ hypertension control in Africa by 2025. Cardiovasc J Afr 28: 261 272. Link: https://bit.ly/39v83zi

17. Kibret KT, Mesfin YM (2015) Prevalence of hypertension in Ethiopia: a systematic meta-analysis. Public Health Reviews 36: 1-12. Link: https://bit.ly/3cCDdXF

18. Mills KT, Stefanescu A, He J (2020) The global epidemiology of hypertension. Nat Rev Nephrol 16: 223-237. Link: https://bit.ly/31Bwln1

19. Forouzanfar MH, Liu P, Roth GA (2017) Global Burden of Hypertension and Systolic Blood Pressure of at Least 110 to 115 mm Hg, 1990-2015. JAMA 317: 165-182. Link: https://bit.ly/3rzOs7u

20. Nguyen Manh T, Bui Van N, Le Thi H, Vo Hoang L, Nguyen Si Anh H, et al. (2019) Pregnancy with Heart Disease: Maternal Outcomes and Risk Factors for Fetal Growth Restriction. Int J Environ Res Public Health 16: 2075. Link: https://bit.ly/3fw8Svz

21. Forouzanfar MH, Liu P, Roth GA, Ng M, Biryukov S, et al. (2017) Global Burden of Hypertension and Systolic Blood Pressure of at Least 110 to $115 \mathrm{~mm} \mathrm{Hg}$, 1990-2015. JAMA 317: 165-182. Link: https://bit.ly/3m6vWCA

22. Adeloye D, Basquill C (2014) Estimating the Prevalence and Awareness Rates of Hypertension in Africa: A Systematic Analysis. PLoS One 9: e104300. Link: https://bit.ly/3cGSuqm
23. Egan BM, Kjeldsen SE, Grassi G, Esler M, Mancia G (2019) The global burden of hypertension exceeds 1.4 billion people: should a systolic blood pressure target below 130 become the universal standard? J Hypertens 37: 1148-1153. Link: https://bit.ly/2PssUfQ

24. van de Vijver S, Akinyi H, Oti S, Olajide A, Agyemang C, et al. (2013) Status report on hypertension in Africa - Consultative review for the 6th Session of the African Union Conference of Ministers of Health on NCD's. Pan Afr Med J 16: 38. Link: https://bit.ly/3m8BH2u

25. Hill JR, Conner RS (2016) Use of Home Monitoring to Improve Blood Pressure Control. Journal for Nurse Practitioners 12: e423-425. Link: https://bit.ly/31BGgZP

26. McGrath BP (2015) Home monitoring of blood pressure: Diagnostic Test. Australian prescriber 38: 16-18. Link: https://bit.ly/3sH2aa0

27. Lau E, Kaczorowski J, Karwalajtys T, Dolovich L, Levine M, et al. (2006) Blood Pressure Awareness and Self-Monitoring Practices among Primary Care Elderly Patients. Can Pharm J 139: 34-41. Link: https://bit.ly/3fw0DzV

28. Hadithi DA, Nazm AS, Khan SA (2012) Self Monitoring of Blood Pressure (SMBP) among Hypertensive patients in Muscat- A pilot study. Journal of Applied Pharmaceutical Science 2. Link: https://bit.ly/3sMsUWM

29. Viera AJ, Cohen LW, Mitchell CM, Sloane PD (2014) Use of Home Blood Pressure Monitoring by Hypertensive Patients in Primary Care: Survey of a Practice-Based Research Network Cohort. J Clin Hypertens (Greenwich) 10 280-286. Link: https://bit.ly/3u6Fi30

30. Baral-Grant S, Haque MS, Nouwen A, Greenfield SM, McManus RJ (2012) Self Monitoring of Blood Pressure in Hypertension: A UK Primary Care Survey. Int $J$ Hypertens 2012: 58206. Link: https://bit.ly/3sKlkvM

31. Huanhuan H, Gang L, Takashi A (2013) How hypertensive patients in the rural areas use home blood pressure monitoring and its relationship with medication adherence: A primary care survey in China 3: 510-516. Link: https://bit.ly/3m8WPFX

32. Breaux S, Tonya L, Brown KC, Erica R (2012) Prevalence of Blood Pressure SelfMonitoring, Medication Adherence, Self-Efficacy, Stage of Change, and Blood Pressure Control Among Municipal Workers With Hypertension. Workplace Health Saf 60: 1-13. Link: https://bit.ly/3wjUxIA

33. Ostchega Y, Zhang G, Kit BK, Nwankwo T (2017) Factors Associated With Home Blood Pressure Monitoring Among US Adults: National Health and Nutrition Examination Survey, 2011-2014. Am J Hypertens 30: 1126-1132. Link: https://bit.ly/3m8fEcc

34. Zahid H, Amin A, Amin E, Waheed S, Asad A, et al. (2017) Prevalence and Predictors of Use of Home Sphygmomanometers Among Hypertensive Patients. Cureus 9: e1155. Link: https://bit.ly/3wiHtDh

35. Tan NC, Khin LW, Pagi R (2005) Home blood-pressure monitoring among hypertensive patients in an Asian population. J Hum Hypertens 19: 559-564 Link: https://bit.ly/3dj4WM8

36. Cuspidi C, Meani S, Fusi V, Salerno M, Valerio C, et al. (2004) Home blood pressure measurement and its relationship with blood pressure control in large selected hypertensive population. J Hum Hypertens 18: 725-731. Link: https://bit.ly/3wiHqr5

37. Konlan KD, Afam-Adjei CJ, Afam-Adjei C, Oware J, Appiah TA, et al. () Practice and Sociodemographic Factors Influencing Self-Monitoring of Blood Pressure in Ghanaians with Hypertension. Int J Chronic Dis 1-7. Link: https://bit.ly/3rzMGDm

Copyright: (c) 2021 Wake AD, et al. This is an open-access article distributed under the terms of the Creative Commons Attribution License, which permits unrestricted use distribution, and reproduction in any medium, provided the original author and source are credited.

Citation: Wake AD, Bekele DM, Bekele YA, Tuji TS, Jaleta DT (2021) The effect of the sociodemographic determinants of self-monitoring of blood pressure. J Cardiovasc Med Cardiol 8(2): 032-037. DOI: https://dx.doi.org/10.17352/2455-2976.000166 